\title{
Eco-efficiency analysis of an innovative packaging production: case study
}

\author{
Katarzyna Joachimiak-Lechman ${ }^{1}$ (D) · Jarosław Selech ${ }^{2} \cdot$ Jędrzej Kasprzak $^{2}$
}

Received: 26 July 2018 / Accepted: 3 November 2018 / Published online: 13 November 2018

(c) The Author(s) 2018

\begin{abstract}
The article presents a two-dimensional comparison of the alternative manufacturing processes of laminates used in food industry packaging. The main aim of the presented study was an assessment of potential environmental impacts occurring during the production of two-layer laminates containing a patented polypropylene film Metallyte ${ }^{\mathrm{TM}}$ 28UBW-ES and the hitherto used pap/LDPE/A1/LDPE multilayer laminates. The environmental assessment was supplemented by a cost calculation with special regard to the investment required for the production of the two-layer laminates. In the research both the life cycle assessment and the life cycle cost methods were applied. Based upon the obtained environmental impact indicator and the discounted costs the eco-efficiency indicator was determined. The results of the comparative analysis are shown on a two-dimensional eco-efficiency diagram. Based on the conducted study it was found that replacement of traditional packaging materials by laminates containing the Metallyte ${ }^{\mathrm{TM}}$ 28UBW-ES structure is justified. This is illustrated by a higher eco-efficiency indicator. The difference in the costs between the manufacturing processes under analysis is relatively small. However, when it comes to the environmental impact, there is a clear disproportion in favor of the two-layer laminates.
\end{abstract}

Katarzyna Joachimiak-Lechman

katarzyna.joachimiak-lechman@ue.poznan.pl

1 Faculty of Commodity Science, Poznan University of Economics, Al. Niepodległosci 10, 60-967 Poznan, Poland

2 Institute of Machines and Motor Vehicles, Poznan University of Technology, ul. Piotrowo 3, 60-965 Poznan, Poland 


\section{Graphical abstract}

\section{Eco-efficiency analysis of an innovative packaging production - case study}

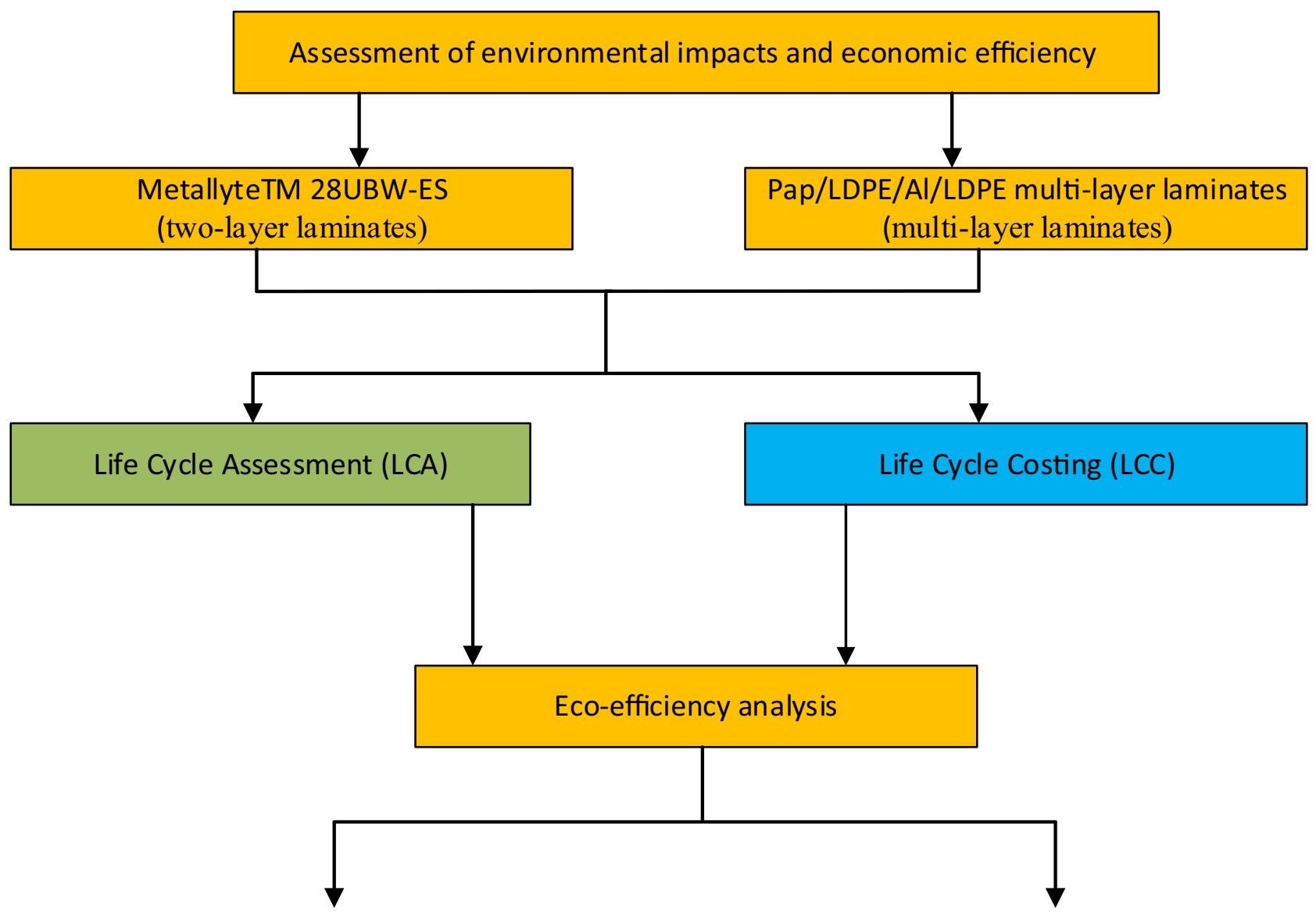

Eco-efficiency analysis
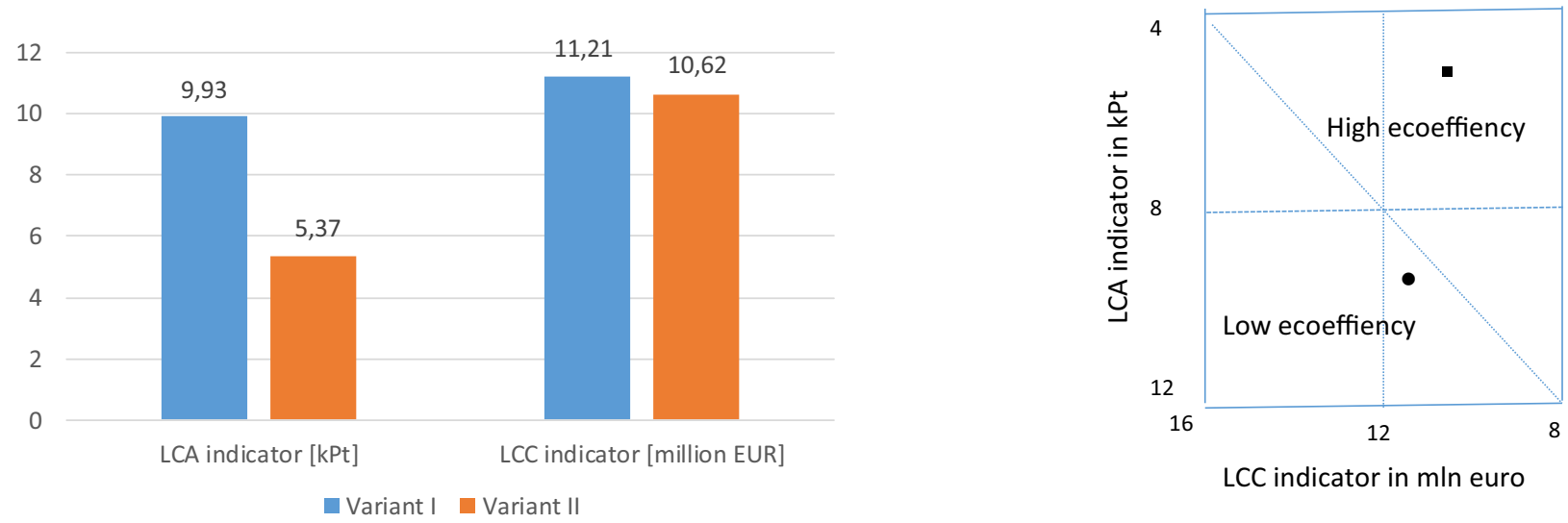

Keywords Eco-efficiency $\cdot$ Environmental aspects $\cdot$ Costs $\cdot$ Laminates 


\section{Introduction}

Laminates are multilayer materials, widely used in various industrial branches. Presently, there is a trend of designing packaging materials in a way that not only guarantees the fundamental functions of the packaging but also considers the ecological characteristics. As a result, innovative twolayer laminates were developed. In the structure of those laminates there is the patented polypropylene Metallyte ${ }^{\mathrm{TM}}$ 28UBW-ES film which may be bonded with paper or biaxially oriented polypropylene (BOPP) or polyester (BOPET) film. These laminates have a smaller weight, higher mechanical strength and bending strength and finally lower migration coefficients when compared to traditional packing. 28UBW-ES film is certified for coming into contact with food products, which makes it fit for use in a large number of food industry branches.

Another factor influencing the quality of laminates manufactured is the printed space which depends, among other things, on the printing method determining the image resolution, type of print substrate, image size, method of refinement, if any, parameters of the printing press and drying method. A new generation of EB (Electron Beam) drying technology consists in accelerating low energy electrons and may be applicable, for instance, in flexography and offset printing (Selech and Prokop 2013). In comparison with other drying technologies EB can offer a possibility of print running with lower energy consumption. EB paints contain no toxic volatile substances and solvents; nor do they cause migration of VOC (volatile organic compounds) into products. Furthermore, the print has a resistance to mechanical and chemical agents. Therefore, it is justified to replace traditional packaging materials with laminates containing the 28UBW-ES structure, and their application in view of modern EB drying technology contributes to a further improvement of environmental aspects.

In the presented paper a quantification of environmental impact generated by the process of two-layer laminates production (paper/28UBW-ES film) and comprehensive assessment of their manufacturing costs were performed. Thus, the analyzed investment project has been considered in the context of its eco-efficiency in the assumed period of use of the production technology. A comparison was also made with the production of the laminate versions used hitherto. The product's eco-efficiency is measured instead in the context of its physical life cycle-from the designing stage, through its manufacturing and use until the final management. The eco-efficiency analysis of the investment project is focused upon the respective stages of project execution, from the pre-investment phase, through the operational phase until the project liquidation.
In compliance with the definition of the World Business Council for Sustainable Development (WBCSD), the eco-efficiency consists in supplying competitively priced goods and services that satisfy human needs and bring quality of life while progressively reducing environmental impacts of goods and resource intensity throughout the entire life cycle to a level at least in line with the Earth's estimated carrying capacity (DeSimone and Popoff 2000). According to the definition given in Standard 14045:2012, eco-efficiency is an aspect of sustainability relating the environmental performance of a product system to its product system value (ISO 14025:2012, p. 5). Product system value should be understood as worth or desirability ascribed to a product system that may encompass different value aspects, including functional, monetary, esthetic, etc. For a longer time, the ideas of life cycle approach and eco-efficiency have become increasingly practical and have been applied in various sectors of economy (e.g., Saling 2005; Kulczycka 2011; Czaplicka-Kolarz et al. 2011; Ristimäki et al. 2013; Szilágyi et al. 2017; Zhang et al. 2018; Shi et al. 2018)—among others in packaging industry. Eco-efficiency analyses in the packaging industry cover both production of packaging materials-viz. the subject of this article-and the final management of packaging waste (e.g., TNO-report 2001; Yabar and Morioka 2007; Czaplicka-Kolarz et al. 2010; Vercalsteren et al. 2010; Marcotte et al. 2010).

\section{Materials and methods}

\section{Initial assumptions: goal and scope of the study}

This study has compared the base (I) and alternative (II) manufacturing variants for laminates used for making food packaging. For this purpose, in the first case environmental aspects and manufacturing costs of traditional multilayer laminates were analyzed in a 10-year manufacturing cycle. Then, the environmental impacts and the costs of introducing a new product (two-layer laminate) into the company's portfolio were investigated. This included the necessary upgrade of the set of printing equipment together with the costs of its further operation as well as sales proceeds after the completion of the project.

The basic product was a four-layer laminate for unit food product packages—-for condiments—a flat bag consisting of:

- paper print substrate,

- aluminum barrier layer,

- two polyethylene layers to guarantee, respectively, appropriate structural strength and sealing 
Table 1 Parameters of compatible packaging materials for the print substrate applied

\begin{tabular}{|c|c|c|c|c|}
\hline Parameter & Pap/PE/Al/LDPE & Pap/28UBW-ES film & $\begin{array}{l}\text { BOPP/28UBW-ES } \\
\text { film }\end{array}$ & $\begin{array}{l}\text { BOPET/28UBW- } \\
\text { ES film }\end{array}$ \\
\hline Basis weight of laminate & $106 \mathrm{~g} / \mathrm{m}^{2}$ & $87 \mathrm{~g} / \mathrm{m}^{2}$ & $44 \mathrm{~g} / \mathrm{m}^{2}$ & $43 \mathrm{~g} / \mathrm{m}^{2}$ \\
\hline Laminate thickness & $90 \mu \mathrm{m}$ & $80 \mu \mathrm{m}$ & $48 \mu \mathrm{m}$ & $40 \mu \mathrm{m}$ \\
\hline Basic weight of print substrate & $50 \mathrm{~g} / \mathrm{m}^{2}$ & $60 \mathrm{~g} / \mathrm{m}^{2}$ & $18.2 \mathrm{~g} / \mathrm{m}^{2}$ & $16.8 \mathrm{~g} / \mathrm{m}^{2}$ \\
\hline Thickness of print substrate & $46 \mu \mathrm{m}$ & $50 \mu \mathrm{m}$ & $20 \mu \mathrm{m}$ & $12 \mu \mathrm{m}$ \\
\hline Basic weight of laminate substrate & $55.8 \mathrm{~g} / \mathrm{m}^{2}$ & $20.7 \mathrm{~g} / \mathrm{m}^{2}$ & & \\
\hline Thickness of laminate substrate & $45 \mu \mathrm{m}$ & $28 \mu \mathrm{m}$ & & \\
\hline Thickness of barrier layer & $7 \mu \mathrm{m}$ & $4.02 \mu \mathrm{m}$ & & \\
\hline $\mathrm{H}_{2} \mathrm{O}$ permeability on laminate substrate & $>0.1 \mathrm{~g} / \mathrm{m} \mathrm{2} / 24 \mathrm{~h}$ & $0.1 \mathrm{~g} / \mathrm{m} 2 / 24 \mathrm{~h}\left(38^{\circ} \mathrm{C}, 90 \% \mathrm{RH}\right)$ & & \\
\hline $\mathrm{O}_{2}$ permeability on laminate substrate & $>0.1 \mathrm{~g} / \mathrm{m} \mathrm{2} / 24 \mathrm{~h}$ & $0.093 \mathrm{~g} / \mathrm{cm} 2 / 24 \mathrm{~h}\left(23^{\circ} \mathrm{C}, 0 \% \mathrm{RH}\right)$ & & \\
\hline Seal strength & $2000 \mathrm{~g} / 25 \mathrm{~mm}$ & $1500 \mathrm{~g} / 25 \mathrm{~mm}$ & & \\
\hline Barrier structure efficiency & $9.4 \mathrm{~m}^{2} / \mathrm{kg}$ & $12 \mathrm{~m}^{2} / \mathrm{kg}$ & & \\
\hline
\end{tabular}

Source: Proprietary study basing upon the company's data and Lapaj (2011)

The alternative laminate is made of two layers, i.e.:

- print substrate,

- Multilayer Metallyte ${ }^{\mathrm{TM}}$ 28UBW-ES film composed of a polypropylene core, vacuum-applied aluminum, EVOH ultra barrier layer and a fast sealing layer.

The intention is to manufacture two-layer laminates on various types of print substrates, i.e., paper, BOPP polypropylene-oriented film and BOPET polyester-oriented film. Table 1 shows the most important parameters of packaging materials under analysis and their respective layers.

The laminates under analysis have different numbers of layers, which directly influences their features (Table 1). However, the strength and barrier parameters of those materials allow maintaining an approximate quality of a product wrapped in standard conditions and in a strictly defined time unit, which in turn, enables their comparison in the context of the application.

The yearly production volume of traditional laminates constitutes $54 \%$ of the Company's total manufacturing output and amounts to 6,391,808 running meters (r.m.) printed ribbon of width of $660 \mathrm{~mm}$. Hence, it was assumed that in the first year, the manufacturing output of new laminates will be on a similar level. $90 \%$ of the above-mentioned volume will be attributed to paper-based laminates, and a $10 \%$ will be attributed to plastic laminates $90 \%$ of which will be BOPP film-based laminates, and 10\% BOPET film laminates. The following increases in the production volume in the successive years are also assumed:

- manufacture year 1 -initial value-6,391,808 r.m.,

- manufacture year $2+5 \%$ on initial value,

- manufacture year $3+5 \%$ on the value from the preceding year,
- manufacture year $4+10 \%$ on the value from the preceding year,

- manufacture year $5+10 \%$ on the value from the preceding year,

- manufacture years 5 to 10 - production volume on a constant level.

The detailed values are presented in Table 2 and they constitute a functional unit (reference flow), for which ecobalance data and costs were collected. ${ }^{1}$

The following unit processes were included in the analyzed production system:

- Base variant—currently used technology—laminate production Pap/PE/Al/LDPE:

- external printing on the substrate in traditional offset technology,

- winding on rolls of a desired width and length (330 mm width $\times 112 \mathrm{~mm}$ height),

- seasoning_intrinsic.

- Alternative variant - technology under considerationproduction of laminates based on $28 U B W-E S$ :

- external printing on the substrate in offset technology with paints fixed by means of EB electron gun (drying under a nitrogen atmosphere),

\footnotetext{
${ }^{1}$ With 1 running meter of a $660 \mathrm{~mm}$ wide $(0.66 \mathrm{~m})$ printed ribbon, 17.86 standard packages with an surface of $0.03696 \mathrm{~m}^{2}$ can be obtained.
} 
Table 2 Production volumes of four-layer and double-layer laminates in particular years of the production cycle (r.m./year)

\begin{tabular}{lllll}
\hline $\begin{array}{l}\text { Year of the pro- } \\
\text { duction cycle }\end{array}$ & \multicolumn{4}{l}{ Production output in r.m. in relations to the print substrate } \\
\cline { 2 - 5 } & Pap/PE/Al/LDPE & Pap/28UBW-ES film & $\begin{array}{l}\text { BOPP/28UBW-ES } \\
\text { film }\end{array}$ & $\begin{array}{l}\text { BOPET/28UBW- } \\
\text { ES film }\end{array}$ \\
\hline n1 & $6,391,808$ & $5,752,627$ & 63,918 & 575,263 \\
n2 & $6,711,399$ & $6,040,259$ & 67,114 & 604,026 \\
n3 & $7,030,989$ & $6,327,890$ & 70,310 & 632,789 \\
n4 & $7,558,314$ & $6,802,482$ & 75,583 & 680,249 \\
n5 & $8,309,351$ & $7,478,416$ & 83,093 & 747,842 \\
n6 & $8,309,351$ & $7,478,416$ & 83,093 & 747,842 \\
n7 & $8,309,351$ & $7,478,416$ & 83,093 & 747,842 \\
n8 & $8,309,351$ & $7,478,416$ & 83,093 & 747,842 \\
n9 & $8,309,351$ & $7,478,416$ & 83,093 & 747,842 \\
n10 & $8,309,351$ & $7,478,416$ & 83,093 & 747,842 \\
\hline
\end{tabular}

Source: Proprietary study basing upon the Company's data

\begin{tabular}{lllll}
\hline Inventory element & Pap/PE/Al/LDPE & $\begin{array}{l}\text { Pap/28UBW- } \\
\text { ES film }\end{array}$ & $\begin{array}{l}\text { BOPP/28UBW- } \\
\text { ES film }\end{array}$ & $\begin{array}{l}\text { BOPET/28UBW- } \\
\text { ES film }\end{array}$ \\
\hline Pap/PE/Al/LDPE laminate [Mg] & 343.92 & - & - & - \\
Paper [Mg] & - & 175.20 & - & - \\
BOPP [Mg] & - & - & 0.59 & - \\
BOPET [Mg] & - & - & - & 4.90 \\
28 UBW-ES film [Mg] & - & 67.16 & & \\
Paint [Mg] & 6.49 & 6.49 & & \\
Glue [Mg] & - & 12.98 & & 157.04 \\
Electricity print [MWh] & 1394.95 & 1046.21 & 17.45 & 40.76 \\
Electricity lamination [MWh] & - & 587.66 & 4.53 & 307.01 \\
Natural gas neutralization of & - & 4745.97 & 34.12 & 15.70 \\
$\quad$ volatile compounds [MWh] & & 157.04 & 1.74 & 0.61 \\
Cutting [MWh] & 174.48 & 6.07 & 0.07 & 12.49 \\
Material handling [MWh] & - & 207.29 & 1.39 & \\
Seasoning [MWh] & - & & & \\
\hline
\end{tabular}

Source: Proprietary study based upon the Company's data
Table 3 Inventory data-the main input flows
- solvent lamination (ethyl acetate) using a two-component polyurethane adhesive and combustion of organic compounds VOC

- winding on rolls of a desired width and length (as in the base variant),

- internal transport with a high-lifting pallet truck, with battery-powered drive and lifting,

- seasoning for 5-7 days in an air-conditioned room with a cubature of approx. $150 \mathrm{~m}^{3}$, equipped with a humidification system, ensuring optimal polymerization conditions: temperature of approx. $25^{\circ} \mathrm{C}$ and humidity of approx. 55\%.

The life cycle of packaging is very specific due to the fact that it is normally used only once, and the scenario of the final management is ambiguous. The presented article focuses on the production phase of the analyzed laminates, recognizing that this is the main hot spot of this product (along with the distribution phase, which is determined by too many factors to constitute the subject of the currently undertaken research). From the LCC point of view, the life cycle of the investment project was considered, therefore, in order to maintain the coherence of the system boundaries, the downstream processes of the packaging life cycle were not included in the LCA analysis.

The consumption of materials was determined on the basis of the company's source documents (current production variant I) and normative values (alternative production option II). The approximate consumption of electricity and heat in both variants was determined based on the installed capacity and performance data as well as working times of individual technological machines. Production wastes were 
assumed at $8 \%$ of the input material for the printing process, $2 \%$ for lamination and $3.2 \%$ for cutting. As a scenario for the final management of production waste, recovery through co-incineration was assumed. Below the main inventory data are presented in accordance to functional unit representing the production volumes (Table 3 ).

In addition to the above-mentioned eco-balance data, material and energy flows occurring in the supply chain were taken into account as part of the undertaken research. Data for these processes were taken from secondary sources (e.g., Ecoinvent database and professional literature).

\section{Environmental life cycle assessment (LCA) and life cycle costing (LCC) - general information}

According to the assumptions of the integrated life cycle analyses (Kloepffer 2008), environmental life cycle assessment and life cycle costing of the investment project were carried out at coherent system boundaries (for processes identified in the base and alternative variants) for an identical functional unit (Table 2) and taking into account the analogous timeframe as well as technological and geographic scope.

The collected eco-balance data were modeled using the IMPACT 2002+ method (Jolliet et al. 2003) and SimaPro software with access to the Ecoinvent database. The IMPACT 2002+ method was chosen because it is representative of European conditions, both in terms of modeling the impact on the environment and normalization streams. Furthermore, this method combines the elements of four other methods (IMPACT 2000, Eco-indicator 99, CML and IPCC) and is a hybrid of modeling methods to the so-called intermediate and final points of the environmental mechanism.

The results of impacts on the environment are expressed in environmental points $[\mathrm{Pt}]$ and in derived units $(\mathrm{mPt}, \mathrm{kPt})$ as a single indicator (Single Score). Positive value of the eco-indicator means negative impact on the environment (environmental loads).

The life cycle cost model included the pre-production, production and post-production phases of the analyzed project. Based on the definition that LCC is the total cost incurred in the life cycle, the following form of the equation was adopted (Frenning et al. 2001):

$\mathrm{LCC}=C_{\mathrm{ic}}+C_{\mathrm{in}}+C_{\mathrm{e}}+C_{\mathrm{o}}+C_{\mathrm{m}}+C_{\mathrm{s}}+C_{\mathrm{env}}+C_{\mathrm{d}}$

where LCC-total cost incurred in the life cycle; $C_{\mathrm{ic}}$-initial investment cost; $C_{\text {in }}$-installation and commissioning costs; $C_{\mathrm{e}}$ - energy cost; $C_{\mathrm{o}}$-operating cost; $C_{\mathrm{m}}$-maintenance and repairs costs; $C_{\mathrm{s}}$-down time, loss of production; $C_{\text {env }}$ - environmental costs; $C_{\mathrm{d}}$ - disposal costs.

The costs were set at constant prices for the reference period (n1), in the European currency. The analysis was carried out taking into account the real discount rate of 5\%. The costs actually incurred were determined by the engineering method of cost estimation (base variant I) and planned costs (alternative variant II) were determined based on estimation by analogy. In order to settle indirect costs, subdivision keys based on the number of working-hours and machine-hours (used for the allocation of eco-balance data) were applied.

Based on the determined environmental impact indicators (LCA) and the LCC indicator representing the discounted stream of life cycle costs and depicting the cost of producing a product unit equivalent to the functional unit adopted in the LCA analysis, the eco-efficiency indicator was determined and its mathematical formula is as follows (CzaplickaKolarz et al. 2011):

Eco-efficiency $=\frac{1}{\mathrm{LCC} \times \mathrm{LCA}}$

A comparative analysis is presented in the chart, placing the obtained results in areas representing different levels of efficiency. Production process characterized by a lower value of the eco-efficiency indicator will be considered less eco-efficient.

The analysis of eco-efficiency could be complemented by the social aspects of the project under investigation. Nevertheless, due to the complexity of the issues presented, it was decided to only indicate this problem in the Discussion section.

\section{Case study: Results}

\section{Assessment of environmental aspects}

The environmental impact of the pap/PE/Al/LDPE laminates production in relation to the functional unit, which is the total volume of the analyzed laminates in the ten-year production period (Table 2) is $9.93 \mathrm{kPt}$. The production of an analogous number of laminates with the 28UBW-ES structure generates a lower environmental impact amounting to $5.37 \mathrm{kPt}$ (Fig. 1). The difference in the values of environmental indicators of laminates that make up the base variant and the alternative variant is therefore almost $46 \%$.

For proper depiction and comparison of environmental interactions of multilayer and two-layer laminates, the environmental loads of the unit laminate production ( 1 r.m.) are presented, broken down into printable substrates (Fig. 2). In unitary terms, a traditional four-layer composite has a significantly greater negative environmental impact than a laminate with a 28UBW-ES structure based on paper, BOPET film and BOPP film (the difference in eco-indicator values is 46,48 and 55\%, respectively). After analyzing the distribution of environmental impact of laminates using the 28UBWES film, it can be concluded that the packaging materials based on BOPP polypropylene film are characterized by 
Fig. 1 Environmental impacts of the laminate production expressed as the results of the cumulative Single Scorebroken down into printable substrates
12.00
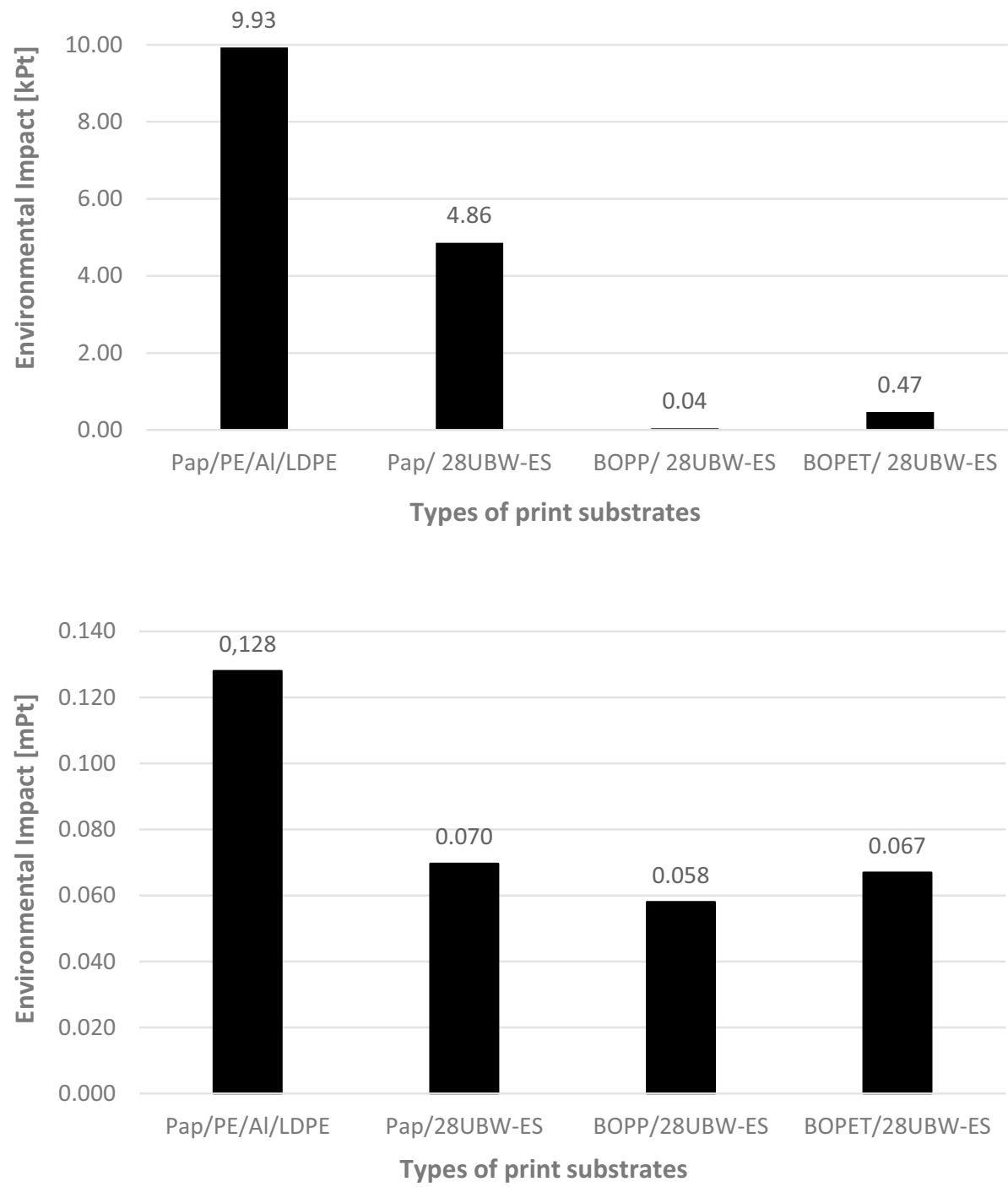

Fig. 3 Impact on the environment of the production of $1 \mathrm{rm}$ of laminates expressed as the results of the cumulative Single Score-broken down into printable substrates (from the point of view of materials consumption and production processes)
Fig. 2 Impact on the environment of the production of $1 \mathrm{rm}$ results of the cumulative Single Score-broken down into printable substrates

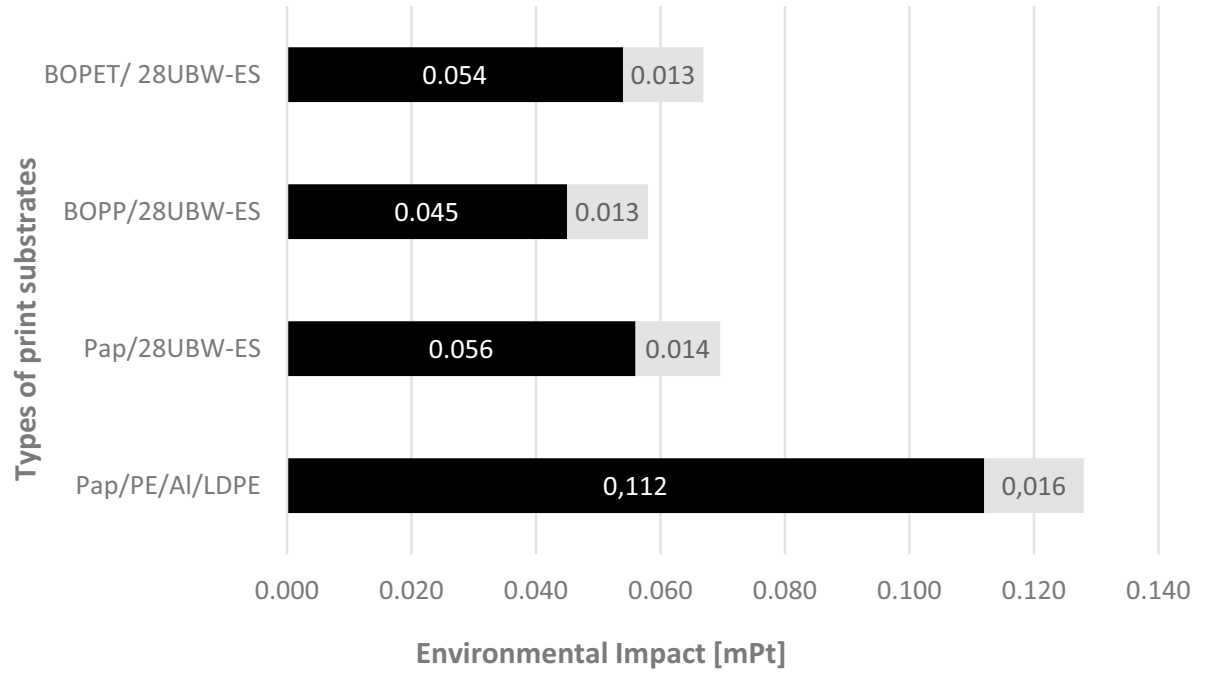

Materials consumption Production processes 
Table 4 Annual production costs of four-layer and double-layer laminates (EUR/Year n1)

\begin{tabular}{|c|c|c|c|c|c|}
\hline \multirow[t]{2}{*}{ Cost category } & \multirow[t]{2}{*}{ Specification } & \multicolumn{2}{|l|}{ Variant I } & \multicolumn{2}{|l|}{ Variant II } \\
\hline & & (EUR) & $(\%)$ & (EUR) & $(\%)$ \\
\hline \multicolumn{2}{|l|}{ Energy cost } & 8397 & 0.71 & 12.262 & 1.12 \\
\hline \multirow[t]{4}{*}{ Operating cost } & Basic materials consumption & 939,480 & 79.14 & 745066 & 67,88 \\
\hline & Auxiliary materials consumption & 1105 & 0.09 & 23171 & 2,11 \\
\hline & Leasing & 62,138 & 5,23 & 67098 & 6,11 \\
\hline & Depreciation & 7364 & 0,62 & 54768 & 4,99 \\
\hline \multirow[t]{2}{*}{ Maintenance and repairs cos } & Staff costs & 156,226 & 13,16 & 181035 & 16,49 \\
\hline & $\begin{array}{l}\text { Repairs and technical efficiency } \\
\text { maintenance costs }\end{array}$ & 3003 & 0,25 & 3491 & 0,32 \\
\hline \multicolumn{2}{|l|}{ Down time, loss of production } & 7764 & 0.65 & 9490 & 0.86 \\
\hline \multicolumn{2}{|c|}{$\begin{array}{l}\text { Environmental cost (waste disposal, environmental fees for introducing emissions into the } \\
\text { air) }\end{array}$} & 1611 & 0.14 & 1313 & 0.12 \\
\hline \multicolumn{2}{|l|}{ Total } & $1,187,088$ & 100 & $1,097,694$ & 100 \\
\hline
\end{tabular}

Source: Proprietary study basing upon the company's data

the relatively best environmental properties. This material exhibits 13\% lower environmental impacts than BOPETbased laminates and $17 \%$ lower environmental impacts than paper-based laminates.

Figure 3 shows the environmental loads of the unitary production of laminates (1 r.m.) divided into printable substrates, demonstrating the share of materials consumption and production processes. It is worth noting that the vast majority of the loads are related to the use of production materials, while the impacts related to production processes are at a similar level for 1 r.m. of all types of laminates (approximately 13-16 $\mu \mathrm{Pt}$ ). This fact indicates that the basic determinant of the level of environmental burdens is the choice of materials for the individual layers of packaging.

It is worth noting, however, that a more detailed analysis of the obtained results (characterization, damage assessment) indicates that the advantage of packaging materials based on BOPP polypropylene film is only visible for damage categories related to the impact on human health, the quality of ecosystems and climate changes. For the category of damage related to the depletion of resources, a slightly lower (by approx. 6-7\%) level of burdens for paper substrates was observed. This results mainly from higher values of environmental burden indicators for the impact category related to the depletion of nonrenewable energy sources. Another noteworthy aspect is that the negative impact of packaging materials based on BOPP polypropylene film associated with the emission of carcinogens is nearly twice as high (compared to other substrates). However, the results of the characterization and damage assessment phase, although interesting and providing information on the detailed structure of environmental burdens, do not bring significant changes in the interpretation of the obtained results of the eco-efficiency of packaging material production processes.

\section{Assessment of costs}

\section{Pre-production phase costs}

In the pre-production phase, the initial investment costs as well as assembly and commissioning costs are incurred. In the case of an alternative variant of laminate production, they are related to the acquisition of fixed assets involved in the production process (regenerative thermal afterburner, Laminastar Combi laminator, Jurmet Winder, Pegaso Lift roll carriage, wetting system for seasoning purposes, humidification system within laminating machines) and research related to the launch of a new product on the market (analysis of the cost-effectiveness of implementing new technology, analysis of environmental impacts).

\section{Production phase costs}

The production phase generates costs related to the implementation of the investment project and consists of several dozen cost categories, which are presented in Table 4 in a synthetic way. The annual costs of the production phase are presented below (the first year) and in most cases are regular variable costs (generated every year, depending on the volume of production). Some of the presented costs do not depend - or only to a limited extent - on the production volume but occur cyclically (e.g., costs of maintaining technical efficiency: replacement, inspection and maintenance) or are generated temporarily - only in the first periods of the project duration (depreciation, leasing costs). 
When comparing the costs of producing four- and twolayer laminates, a significant decrease by almost $21 \%$ in the cost of basic materials was recorded and both the former and the latter variant of laminate production have the largest share in total production costs (Table 4). The remaining costs of producing double-layer laminates are higher than those of the traditional equivalents. The biggest changes were observed in the costs of auxiliary material consumption followed by depreciation and energy costs. In the first year of analysis, the cost of repairs and maintenance of the technical efficiency of the machinery park involved in the production of double-layer laminates is slightly higher than in the case of traditional laminates. However, in subsequent years of analysis, these costs increase significantly due to the expiration of the laminator warranty period and the costs of necessary replacements. The share of the costs discussed above in the total annual costs of producing double-layer laminates is so low (Table 3) that they do not eliminate the benefits resulting from the reduction of the costs of basic materials. Finally, the production cost (in the first year of production) of laminates containing the 28UBW-ES structure is lower than the analogous number of traditional laminates. The production costs of double-layer laminates decreased by $7.53 \%$ compared to multilayer laminates. According to the assumptions (Table 2), the production volume of analyzed laminates increases, which entails the increase in variable costs as well as an increasing share of fixed costs in the total production costs, which are accounted for in accordance with the division keys based on the machine-hours. The total costs of subsequent production years are presented in Table 5, and they appear in the discounted form.

\section{Post-production phase costs}

In the post-production phase, costs associated with the dismantling and liquidation of the investment project are incurred. At this stage, it is also possible to generate income from the sale of fixed assets with their residual value. Such a variant was adopted in the conducted study, and the resale of the laminator and the regenerative thermal afterburner were assumed. The residual value of the laminator was set at $20 \%$ of the purchase value, while the afterburner at $35 \%$ of the purchase value.

\section{Discount analysis}

An element of cost analysis appearing at different times in the future is discounting. Discounting is a process of calculating the present (current) value (PV) of future costs, and for this purpose, the following formula applies:

$\mathrm{PV}=\frac{\mathrm{FV}}{(1+k)^{n}}$

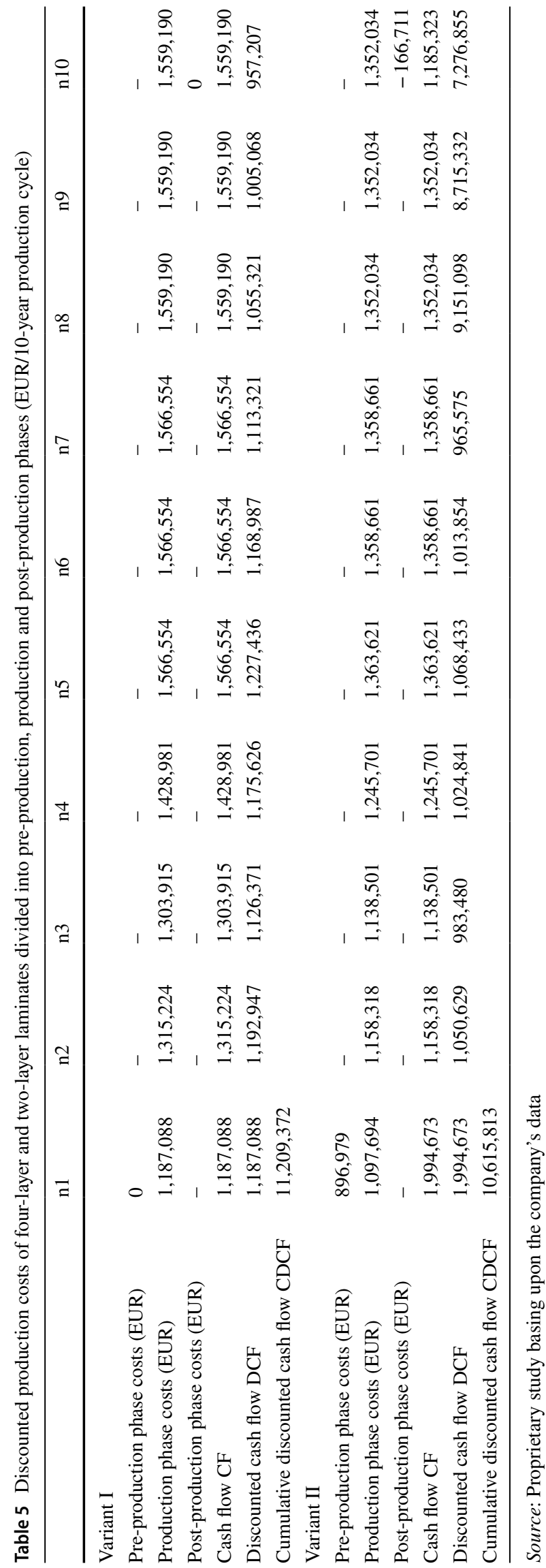


Table 6 Eco-efficiency analysis

\begin{tabular}{lcc}
\hline Type of indicator & Variant I & Variant II \\
\hline LCA indicator (kPt) & 9.93 & 5.37 \\
LCC indicator (million EUR) & 11.21 & 10.62 \\
Eco-efficiency indicator & 0.009 & 0.018 \\
\hline
\end{tabular}

Source: Proprietary study basing upon the Company's data

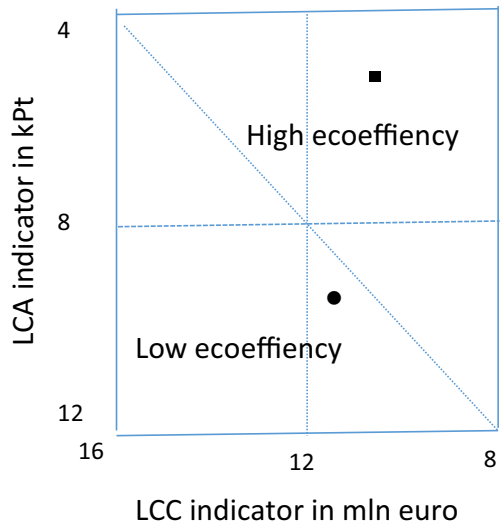

Fig. 4 Eco-efficiency analysis

where $\mathrm{PV}$ - present value of the future cost; FV-future value; $k$-real discount rate; $n$-next period of the life cycle.

Table 5 presents the costs of individual phases of the production cycle of two variants of laminate production. The purchase of a winder which will replace the worn-out machine for cutting paper-based laminates is excluded from the initial investment costs as its purchase is independent of the planned implementation of the technology for the production of double-layer laminates. Revenues from the sale of fixed assets (alternative variant II) were included in the costs of the post-production phase as a negative value.

When analyzing the total annual costs of producing innovative laminates, it was noticed that in the first year they are lower than the analogous costs of manufacturing traditional laminates and this trend is maintained in the subsequent years of analysis. The total discounted life cycle costs determined for the investment project consisting in the implementation of the technology for the production of double-layer laminates are lower than the discounted costs of the production cycle of traditional laminates by just over $5 \%$.

\section{Eco-efficiency analysis}

The eco-efficiency analysis allows the selection of a more favorable version of the compared products/processes (technologies), taking into account conflicted criteria (trade-off analysis). In the analyzed case, from the point of view of both environmental and cost issues, laminates with the
28UBW-ES structure proved to be a better version of the packaging material, which is shown by a higher eco-efficiency indicator (Table 6). Figure 4 shows the environmental and cost dimension, as well as the symbols denoting the compared variants of producing laminates for food packaging (the dot-variant I, the square-variant II). Variant II representing laminates with the 28UBW-ES structure is in the area of high efficiency and while the cost difference between the analyzed production systems is relatively small, in the case of environmental impacts a clear disproportion in favor of two-layer laminates is visible.

\section{Discussion}

When implementing an integrated life cycle analysis, the LCA and LCC methodology should be as consistent as possible. However, some discrepancies cannot be avoided, and they also occurred in the case of the presented research. Dissonance was identified, among others in the aspect of:

- depreciation-LCA often ignores the consumption of fixed assets as a result of their use. Although in some LCI databases certain technical aspects are taken into account, the problem arises when constructing inventory tables for specific technological processes, in which the physical consumption of fixed assets should be included. In LCC research, depreciation is a compulsory element of cost analysis.

- time-space integration-in LCA studies, the aspect of time and location of environmental intervention is usually omitted. The discounting of environmental damage is debatable and not recommended by specialists, which makes the LCA a "steady-state" analysis. LCC analysis is performed using dynamic methods for assessing cash flows.

- characterization parameters-characterization parameters determined for environmental interventions falling within the scope of individual impact categories under a given LCIA method, are common for all analyzed products. On the other hand, costs which somehow correspond to characterization parameters in the LCA may be different, not only in relation to the analyzed products, but also in relation to the "places" of unit processes in one product system.

Considering the results of the environmental analyses conducted with the use of LCA, it can be concluded that for the adopted functional unit covering the annual volume of packaging production using various material variants (traditional four-layer laminate and 28UBW-ES structured laminates on various substrates), there are significant 
differences in the level of environmental burdens, which results mainly from differences in the volume of packaging produced using each of the materials. However, also for the reference functional unit covering the ( 1 r.m.) production of layered laminates, significant differences in the level of environmental burdens can be observed. Relatively highest eco-indicators are presented in the traditional fourlayer laminate produced with the use of paper, aluminum film and plastics-in whose case environmental loads are more than twice as high as in the case of packaging materials produced with $28 \mathrm{UBW}-\mathrm{ES}$ on various substrates. It is also worth noting that the basic determinant of the level of environmental burdens is the type of material. Remaining aspects of analyzed production processes are much less important.

When considering the complex costs of producing laminates with the 28UBW-ES structure, it should be stated that the total discounted costs of the ten-year production cycle of two-layer laminates are lower than those of their traditional counterparts. The LCC ratio determined, however, refers to the cost-effectiveness of the investment project under analysis and does not prejudge its economic efficiency. In order to assess the economic efficiency of the investment, the NPVLC (Net Present Value in Life Cycle) method should be used. In the recent study, the NPV indicator was omitted because the fact that two-layer laminates have lower unit costs potentially allows the company to apply a higher markup on costs and thus achieve a higher sales profit.

Life Cycle Sustainability Assessment (LCSA) has been proposed as a result of the development of life cycle assessment approaches and is a tool that integrates environmental, economic and social aspects. The social dimension has not been included in the scope of the presented research because, considering the implementation of new laminates for production, no differences in the assessment of individual social categories related to, for example, working conditions, human rights, product liability, etc. have been identified. However, many environmental aspects regarding the analyzed laminates can constitute important social issues. The analyzed laminates for the production of packaging differ in their weight. The reduction of the unit weight of packaging clearly influences the goods trade, e.g., in the aspect of transport emissions, which cause a deterioration of the air quality that is noticeable to the public. Lighter packaging also means less problematic waste at the final stage of the management, which may be important for the local community, threatened by the proximity of the garbage dump.

The study assumes that the scenario for the final life phase of packaging waste is its storage, because in the current technological conditions recycling processes for light multi-material products are inefficient. Therefore, the analysis of environmental issues related to transport and utilization processes (for the given assumption) does not require environmental modeling (i.e., inclusion in the LCA framework) as these aspects are mainly influenced by the unit weight of the packaging. From this point of view, doublelayer laminate is also a better version of the tested product. Scenarios taking into account recycling and energy recovery in relevant industrial installations will be considered in the future, presumably with the assessment based on Circular Footprint Formula (CFF) indicator.

An interesting concept regarding the new food packaging waste management process has been presented in Italy (Vitale et al. 2018). However, such an approach would be difficult to apply in Polish conditions, where industrial waste incineration installations are not yet widely used and there are no structural programs for separating and sorting packaging waste. Moreover, for such a specific packaging as the one considered (very low weight, several layers), sorting and separation processes are not economically efficient and therefore not carried out.

\section{Conclusions}

On the basis of a comparative LCA and LCC study of the production of alternative laminates for food packaging, it was considered appropriate to substitute traditional packaging materials with 28UBW-ES-containing laminates. The most important findings are as follows:

- for unit product indicators (1 r.m.) environmental loads for packaging materials manufactured with the use of 28UBW-ES film on various substrates are less than half the size of those of the traditional four-layer laminates with the participation of paper substrates, aluminum film and plastics,

- the lowest level of environmental loads is demonstrated by packaging materials with the use of 28UBW-ES film mounted on a polypropylene substrate (BOPP)—for these materials the values of eco-indicators are almost $20 \%$ lower than in the case of packaging materials with 28UBW-ES film with a polyester substrate and paper,

- the main determinants of the level of environmental burdens for all types of packaging considered are the materials used; the share of other aspects of the production processes-despite the differences-is at a comparable level,

- LCC indicator calculated for the ten-year laminate production cycle with the 28UBW-ES structure, taking into account the pre-production, production and post-production phase is lower than the LCC calculated for the analogous production cycle of traditional laminates,

- the most significant decrease in costs was noted in the area of basic materials consumption (almost 21\%) - this 
is the cost category with the largest share in the total production costs, which prejudges the reduction of the LCC indicator of double-layer laminates.

Open Access This article is distributed under the terms of the Creative Commons Attribution 4.0 International License (http://creativeco mmons.org/licenses/by/4.0/), which permits unrestricted use, distribution, and reproduction in any medium, provided you give appropriate credit to the original author(s) and the source, provide a link to the Creative Commons license, and indicate if changes were made.

\section{References}

Czaplicka-Kolarz K, Burchart-Korol D, Krawczyk P (2010) Ecoefficiency analysis methodology on the example of the chosen polyolefins production. J Achiev Mater Manuf Eng 43:469-475

Czaplicka-Kolarz K, Burchart-Korol D, Śliwińska A, Krawczyk P, Ludwik-Pardała M (2011) Eco-efficiency of underground coal gasification technology-methodology and previous experience (in Polish). Min Rev 67(10):33-40

DeSimone LD, Popoff F (2000) Eco-efficiency: the business link to sustainable development. MIT Press, Cambridge

TNO Environment, Energy and Process Innovation (2011) Eco efficiency of recovery scenarios of plastic packaging. Report $\mathrm{R}$ 2000/119. Netherlands. www.plasticseurope.org/Documents/ Document/20100311161403TNO_study_Ecoefficiency_of_recov ery_scenarios_of_plastic_packaging.pdf. Accessed 20 June 2017

Frenning L, Hovstadius G, Alfredsson K, Beekman B, Angle T, Bower J, Hennecke FW, McKane A, Doolin J, Romanyshyn G (2001) Pump life cycle cost: a guide to LCC analysis for pumping systems. Europump and Hydraulic Institute, Brussels

Jolliet O, Margni M, Charles R, Humbert S, Payet J, Rebitzer G, Rosenbaum R (2003) IMPACT 2002+: a new life cycle impact assessment methodology. Int J Life Cycle Assess 8:324-330

Kloepffer W (2008) Life cycle sustainability assessment of products. Int J Life Cycle Assess 13(2):89-95

Kulczycka J (2011) Eco-efficiency of investment projects using the product's life cycle concept (in Polish). The Mineral and Energy Economy Research Institute PAN, Cracow
Lapaj M (2011) Potential ecological impact of packaging films from Cykoria S.A. High-barrier foils MetallyteTM. (in Polish) ExxonMobil, Chemical, Luksemburg

Marcotte M, Arcand Y, Maxime D, Landry D (2010) Development of eco-efficiency indicators to assess the environmental performance of the canadian food and beverage industry. In: Aguilera J, Simpson R, Welti-Chanes J, Bermudez-Aguirre D, Barbosa-Canovas $\mathrm{G}$ (eds) Food engineering interfaces. Food engineering series. Springer, New York

PN-EN ISO 14045 (2012) Environmental management—eco-efficiency assessment of product systems-principles, requirements and guidelines

Ristimäki M, Säynäjoki A, Heinonen J, Junnila S (2013) Combining life cycle costing and life cycle assessment for an analysis of a new residential district energy system design. Energy 63:168-179

Saling P (2005) Eco-efficiency analysis of biotechnological processes. Appl Microbiol Biotechnol 68(1):1-8

Selech J, Prokop M (2013) Electron beam-modern technology in the soft packaging industry (in Polish). Food Ind 8:70-72

Shi J, Wang Y, Fan S, Ma Q, Jin H (2018) An integrated environment and cost assessment method based on LCA and LCC for mechanical product manufacturing. Int J Life Cycle Assess. https://doi. org/10.1007/s11367-018-1497-x

Szilágyi A, Bodnárné Sándor R, Gröller G, Szita K (2017) The connection of life-cycle thinking with the European Commission's Circular Economy Strategy in the Central Eastern European region. Conference: SETAC Europe 27th annual meeting, Brussel

Vercalsteren A, Spirinckx C, Geerken T (2010) Life cycle assessment and eco-efficiency analysis of drinking cups used at public events. Int J Life Cycle Assess 15(2):221-230

Vitale G, Mosna D, Bottani E, Montanari R, Vignali G (2018) Environmental impact of a new industrial process for the recovery and valorisation of packaging materials derived from packaged food waste. Sustain Prod Consum 14:105-121

Yabar H, Morioka T (2007) Eco-efficiency analysis of the plastic recovery systems in Hyogo eco-town project. In: Ishikawa M, Huppes $\mathrm{G}$ (eds) Quantified eco-efficiency. Eco-efficiency in industry and science. Springer, Dordrecht

Zhang Y, Kang H, Hou H, Shao S, Sun X, Qin Ch, Zhang S (2018) Improved design for textile production process based on life cycle assessment. Clean Technol Environ Policy 20(6):1355-1365 